\title{
Beliefs about medicines among prescribing and non-prescribing nurses in Sweden
}

\author{
Ann-Charlotte M Mardby ${ }^{1}$, Annika G Jakobsson ${ }^{2}$, Tove M Hedenrud ${ }^{2}$ \\ 1. Research and Development, Sahlgrenska University Hospital, Gothenburg, Sweden. 2. Department of Public Health and \\ Community Medicine/Social Medicine, University of Gothenburg, Gothenburg, Sweden.
}

Correspondence: Ann-Charlotte M Mardby. Address: Bruna Stråket 21 pl 3, SE-413 45 Göteborg, Sweden. Email: ann-charlotte.mardby@vgregion.se

Received: December 20, 2013

Accepted: April 28, $2014 \quad$ Online Published: June 11, 2014

DOI : 10.5430/jnep.v4n8p153

URL: http://dx.doi.org/10.5430/jnep.v4n8p153

\begin{abstract}
Background: The beliefs patients and health care providers have about medicines are important for communication about medicines, which is a central tool for patient-centered care and the quality of care. This study aimed to analyze general beliefs about medicines among prescribing and non-prescribing nurses.

Methods: In this cross-sectional study a survey (Beliefs about Medicines Questionnaire, socio-demographic factors, years of professional experience and the right to prescribe) was sent to 303 nurses in Region Västra Götaland, Sweden, in 2007 (response rate: $80.5 \%$ ). Analyses were made with independent $t$-tests, analyses of variance and linear regressions.

Results: The beliefs about medicines among nurse prescribers did not differ from those of non-prescribing nurses. Professional experience was, however, important for harmful beliefs about medicines. Non-prescribing nurses with 16-30 years of professional experience had more harmful beliefs about medicines compared with non-prescribing nurses with less professional experience.

Conclusions: It is important to further examine the possible effects of education and professional experience on beliefs among nurses. During the communication between nurses and patients there is a need for increased awareness of the importance of professional experience for beliefs about medicines.
\end{abstract}

\section{Key words}

Nurses, Prescribing medicines, Beliefs about medicines

\section{Introduction}

Swedish district nurses with a postgraduate diploma in specialist nursing have had the right to prescribe a limited number of medications since 1994. These are mostly medications which are also available as over-the-counter (OTC) preparations. In 2000, the right to prescribe was extended to include other specialist nurses with a documented education in pharmacology and pathology, working in community health care or home nursing ${ }^{[1]}$. This situation is comparable with the US and British nurse practitioners who usually work in outpatient clinics as a specialist in specific diagnose areas ${ }^{[2,3]}$. The patients, usually adults and families, see their nurse practitioners for acute and chronic health problems as well as to maintain health through activities. The US nurse practitioners also recommend OTC preparations and prescribe medicines for already existing and new diagnoses ${ }^{[3]}$. 
Nurse prescribers have expressed that they consider prescribing to be a natural part of the nursing process and that they experience an enhanced sense of professionalism due to their increased knowledge about medication ${ }^{[4]}$. There are obvious benefits of nurses who prescribe medicines, both for the patients and for the nurses themselves, e.g., improved continuity of care for the patient and increased job satisfaction for the nurse ${ }^{[5,6]}$. Improved communication is another beneficial effect of nurses who prescribes medicines, according to nurses ${ }^{[5,6]}$ and patients ${ }^{[7]}$. Nurses' communication about medicines and medication taking behavior has been found to be associated with perceived barriers among patients in terms of how to handle medicines ${ }^{[8]}$, thus interactive communication between nurses and patients is important for maintaining personcentered care $(\mathrm{PCC})^{[9]}$.

PCC comprises a holistic, individualized, respectful and empowering perspective ${ }^{[10]}$ and is a key component of quality health care that emphasizes a partnership between the patients and the healthcare professionals. The partnership is relational and can be seen as a mutual sharing and interdependence ${ }^{[11]}$, which requires high professionalism of nurses.

Within PCC the beliefs of the healthcare provider as well as of the patient are important to consider. It has been suggested that communication about medicines may be affected by different views on or beliefs about medicines ${ }^{[12]}$. Beliefs in general pertain to knowledge ${ }^{[13]}$, and they do not have to be based on facts ${ }^{[14]}$. There are different criteria for the formation of beliefs, one of which is the ease of retrieval. Things that occur frequently are easier to remember; hence, one is more likely to use a piece of belief-relevant knowledge if it is referenced regularly ${ }^{[13]}$. As regards health-related beliefs, it has been argued that the health-related beliefs of health care professionals are objective and professional, rather than personal ${ }^{[15]}$. Therefore, it could be argued that beliefs about medicines will be similar within a specific group of health care professionals. Few studies have focused on describing the beliefs about medicines among nurses ${ }^{[16,17]}$. An Australian study showed that mental health nurses had somewhat negative beliefs about medicines ${ }^{[16]}$. This is consistent with a Swedish study which demonstrated that nurses saw medicines as more harmful and less beneficial compared with doctors ${ }^{[17]}$. No study has, however, analyzed differences in beliefs about medicines considering the nurses right to prescribe medicines or not.

The new authority of nurses as prescribers necessitates new knowledge, and nurse prescribers have expressed an increased interest in drug-related areas (e.g. drug interactions) ${ }^{[4,6]}$. An association between learning and development activities and performance at work has been established among Australian nurses ${ }^{[18]}$. Education in medical science has been found to be one of the most important factors for the knowledge of the work of nurses in a Swedish cross-sectional study ${ }^{[19]}$. In specific, education about medicines was important for beliefs about medicines among Swedish nursing students ${ }^{[20]}$. In the study in question, undergraduate nursing students in their third year believed to a greater extent in the beneficial effects of medicines compared to first-year students. Among Swedish general practitioners professional experience has been found to be of importance for own beliefs about medicines ${ }^{[17]}$. In communication between nurses and patients about medicines, it is important that the patients do not experience doubts about the medication. Based on experiences and beliefs expressed in several studies ${ }^{[4-6,16,17,20]}$, we hypothesized that the right to prescribe may be associated with beneficial beliefs about medicines among nurses.

The aim of this study is to analyze general beliefs about medicines among prescribing and non-prescribing nurses according to socio-demographic factors and personal medicine use.

\section{Methods}

\subsection{Study design}

This cross-sectional questionnaire study is part of a larger project with the overall aim of examining beliefs about medicines among doctors and nurses in Region Västra Götaland, Sweden ${ }^{[17]}$, comprising approximately 1.5 million inhabitants at the time of the data collection. 


\subsection{Study population}

The study base consisted of 1844 nurses who were registered as practicing professionals in Region Västra Götaland, Sweden. They were found via the primary care employee lists supplied by the Pharmaceutical Unit of the Department of Health in Region Västra Götaland. A requirement of 122 participants resulted from a power calculation performed for the data collection on doctors and nurses, where nurses were treated as one group ${ }^{[17]}$. The questionnaire was sent to a sample of 303 randomly selected nurses ( $16 \%$ of the available nurses in the region).

\subsection{Data collection}

Data were collected between February and April 2007 using a questionnaire with one reminder which included the general part of the Beliefs about Medicines Questionnaire (BMQ) ${ }^{[21,22]}$ and questions on socio-demographic factors, personal medicine use, years of professional experience and their certificate for prescribing medicines. An attached letter contained written information about the study and the researchers' contact information. The questionnaires were returned in a pre-stamped envelope.

\subsection{The outcome variable}

In this study general beliefs about medicines was the outcome variable. The outcome was measured with the General BMQ, which has been developed in the UK ${ }^{[21,22]}$. The General BMQ has previously been translated into Swedish from English using a back-translation method, which was accepted by the original author of the questionnaire. General BMQ includes twelve statements which measures the beliefs people have about medicines in general. The outcome variable contains three subparts analyzed separately: General Harm, General Overuse and General Benefit. General Harm measures beliefs about medicines as something harmful. General Overuse measures concerns people have about the possibility that doctors may overprescribe medicines. General Benefit measures beliefs about the benefits of medicines. Responses to the BMQ are given on a five-point Likert scale: $1=$ strongly disagree; $2=$ disagree; $3=$ uncertain; $4=$ agree and $5=$ strongly agree.

The original BMQ has been validated with good results and tested for its psychometric qualities ${ }^{[21]}$. The Swedish version of the General BMQ has been tested in a pilot study with good face validity and used in different groups ${ }^{[17,20,23-26]}$. In the current study, the internal consistency between the General BMQ statements in the different subparts was tested using Cronbach's alpha. The level of internal consistency was 0.66 for General Harm, 0.76 for General Overuse and 0.70 for General Benefit. None of the subparts received a higher Cronbach's alpha value if any of the statements were deleted.

\subsection{Explanatory variables}

The right to prescribe was used as an explanatory variable in this study. The socio-demographic factors used as explanatory variables was sex, age ( $\leq 40,41-50,51-60$, and $\geq 60$ years), country of birth (the Nordic countries, rest of the world), and parents' country of birth (no parent born outside the Nordic countries, $\leq 1$ parent born outside the Nordic countries). Personal medicine use was measured as prior use of medicines (conventional medicines, herbal or homeopathic medicines, not used any medicines), current use (same categories as prior use), and type of medicine currently used (cardiovascular, diabetes, asthma, anesthetic, gastro intestinal, infection, sedative or sleeping, and depression). Years of professional experience was also measured $(\leq 15,16-30, \geq 30$ years $)$.

\subsection{Statistical analyses}

The statistical analyses were performed with IBM Statistical Package for the Social Sciences version 19.0. For each participant, all statements in each General BMQ subpart were summarized and divided by the number of statements included in the subpart (mean value: 1.00-5.00). A higher mean meant a stronger belief in the concept described by that subgroup. A General BMQ subpart received a missing value if a participant had one or more missing values for any of the included statements. 
Univariate analyses were made with independent $t$-tests and ANOVAs (analyses of variance) ${ }^{[27]}$. With multivariate analyses these findings were confirmed using linear regressions ${ }^{[27]}$. With independent $t$-tests differences in beliefs about medicines were analyzed using the dichotomous variable personal use of medicines (prior and current use) within the groups of nurse prescribers and non-prescribing nurses. ANOVAs were used to analyze differences in beliefs owing to age and professional experience within the groups of nurse prescribers and non-prescribing nurses. Any differences found in any ANOVA tests were analyzed with a post hoc test (Tukey). Differences in beliefs about medicines between nurse prescribers and non-prescribing nurses for each age group and professional experience group were tested with independent $t$-tests. Linear regression models were constructed in order to analyze differences in beliefs about medicines (dependent variable) between nurse prescribers (reference group) and non-prescribing nurses as well as to be able to control for socio-demographic variables and personal use of medicines.

This study was carried out in compliance with the Helsinki Declaration and was approved by a regional ethical committee in Sweden, ref. no. 690-06. The decision to send the questionnaire to the home addresses of the nurses was made after considering the possibility that it would be experienced as an invasion of privacy by those who were invited to participate. It was, however, clearly stated in the invitation letter that participation in the study was voluntary and that the participants would be unidentifiable by the researchers. Answered and returned questionnaire was considered as informed consent to participate in the study.

\section{Results}

\section{Background characteristics}

A total of 244 nurses returned the survey (response rate: 80.5\%): 156 nurse prescribers and 88 non-prescribing nurses. The mean age of the nurse prescribers was 52 years old (range: 39-65). The non-prescribing nurses had the same mean age (range: 39-66). A lower proportion of nurse prescribers were over 60 years old, and a larger proportion were between 51 and 60 years old compared to non-prescribing nurses (see Table 1). Most nurse prescribers and non-prescribing nurses stated that they had been born in the Nordic countries. Almost the whole study population also stated that their parents were born in the Nordic countries. The majority (61.4\%) of the nurse prescribers had 16 to 30 years of professional experience as nurses (see Table 1). Approximately half of the non-prescribing nurses had worked as a nurse for between 16 and 30 years, and a third had done so for more than 30 years (see Table 1). The two groups of nurses described similar experiences of prior use of medicines. Almost all of them had prior experience of using conventional medicines (either prescription or OTC medicines). Approximately one-third of the nurse prescribers and $20.9 \%$ of the non-prescribing nurses described prior use of herbal or homeopathic medicine (see Table 1).

According to the independent t-tests, there were no differences in general beliefs about medicines between the nurse prescribers and non-prescribing nurses (see Table 2). This result was also confirmed through univariate linear regression models (see Table 3).

Nurse prescribers who had up to 15 years of professional experience believed medicines to be more harmful compared to non-prescribing nurses (see Table 2). As regards within-group differences in beliefs about the harmful effects of medicines according to professional experience, the trend went in the opposite direction in the two nursing groups (see Table 2). Non-prescribing nurses with 16-30 years of professional experience held stronger beliefs in the harmful effects of medicines compared to non-prescribing nurses with less professional experience (see Table 2). There was no significant difference in beliefs about the harmful effects of medicines between nurse prescribers with at least 31 years of professional experience compared with those with less experience (see Table 2). 
Table 1. Background characteristics of nurse prescribers and non-prescribing nurses in Region Västra Götaland,

Sweden $(n=244)$

\begin{tabular}{|c|c|c|}
\hline & $\begin{array}{l}\text { Nurses prescribers } \\
\% \text { (n) }\end{array}$ & $\begin{array}{l}\text { Non-prescribing nurses } \\
\% \text { (n) }\end{array}$ \\
\hline Total & $63.7(156)$ & $35.9(88)$ \\
\hline \multicolumn{3}{|l|}{$\operatorname{Sex}^{1}$} \\
\hline Women & $98.7(154)$ & $96.6(85)$ \\
\hline Men & $1.3(2)$ & $3.4(3)$ \\
\hline Age (years) $\dagger$ & $*$ & $*$ \\
\hline$\leq 40$ & $2.6(4)$ & $8.0(7)$ \\
\hline $41-50$ & $37.8(59)$ & $34.5(30)$ \\
\hline $51-60$ & $46.8(73)$ & $34.5(30)$ \\
\hline$\geq 61$ & $12.8(20)$ & $23.0(20)$ \\
\hline \multicolumn{3}{|l|}{ Birth country } \\
\hline The Nordic countries & $100.0(156)$ & $98.9(87)$ \\
\hline Rest of the world & 0 & $1.1(1)$ \\
\hline \multicolumn{3}{|l|}{ Parents birth country } \\
\hline $\begin{array}{l}\text { No parent born outside the Nordic } \\
\text { countries }\end{array}$ & $96.8(151)$ & $94.3(82)$ \\
\hline $\begin{array}{l}\leq 1 \text { Parent born outside the Nordic } \\
\text { countries }\end{array}$ & $3.2(5)$ & $5.7(5)$ \\
\hline \multicolumn{3}{|l|}{ Professional experience $\dagger$} \\
\hline$\leq 15$ & $12.3(19)$ & $19.5(17)$ \\
\hline $16-30$ & $60.4(93)$ & $47.1(41)$ \\
\hline$\geq 31$ & $27.3(42)$ & $33.3(29)$ \\
\hline \multicolumn{3}{|l|}{ Prior use of medicines $\uparrow \nmid$} \\
\hline Conventional medicines & $90.3(140)$ & $95.3(82)$ \\
\hline Herbal or Homeopathic medicines & $29.0(45)$ & $20.9(18)$ \\
\hline Not used any medicine & $9.0(14)$ & $3.5(3)$ \\
\hline \multicolumn{3}{|l|}{ Current use of medicines $+\uparrow$} \\
\hline Conventional medicines & $71.0(110)$ & $75.9(66)$ \\
\hline Herbal or Homeopathic medicines & $11.6(18)$ & $10.3(9)$ \\
\hline Do not use any medicine & $24.5(38)$ & $21.8(19)$ \\
\hline \multicolumn{3}{|l|}{ Type of medicine currently used $\uparrow \dagger$} \\
\hline Cardiovascular & $14.8(23)$ & $16.1(14)$ \\
\hline Diabetes & 0 & $3.4(3)$ \\
\hline Asthma & $3.9(6)^{* *}$ & $13.8(12)^{* *}$ \\
\hline Anesthetic & $32.9(51)$ & $34.5(30)$ \\
\hline Gastro intestinal & $9.0(14)$ & $9.2(8)$ \\
\hline Infection & $3.9(6)$ & $6.9(6)$ \\
\hline Sedative or sleeping & $1.9(3)^{*}$ & $8.0(7)^{*}$ \\
\hline Depression & $3.4(5)$ & $4.6(4)$ \\
\hline
\end{tabular}

Note. Missing values not included;

$\dagger \chi^{2}$ test: $* * p<.01, * p<.05$

$\ddagger$ Answered yes if using/used this medicine, test done for each group/medicine respectively between nurse prescribers and non-prescribing nurses 
Table 2. General beliefs about medicines due to background variables and personal medicine use among nurse prescribers and non-prescribing nurses in Region Västra Götaland, Sweden

\begin{tabular}{|c|c|c|c|c|c|c|c|}
\hline & & \multicolumn{2}{|c|}{ General Harm } & \multicolumn{2}{|c|}{ General Overuse } & \multicolumn{2}{|c|}{ General Benefit } \\
\hline & & $\begin{array}{l}\text { Nurse } \\
\text { prescribers } \\
\text { Mean (SD) } \\
(n=147)\end{array}$ & $\begin{array}{l}\text { Non- } \\
\text { prescribing } \\
\text { nurses Mean } \\
\text { (SD) }(n=83)\end{array}$ & $\begin{array}{l}\text { Nurse } \\
\text { prescribers } \\
\text { Mean (SD) } \\
(n=150)\end{array}$ & $\begin{array}{l}\text { Non- } \\
\text { prescribing } \\
\text { nurses Mean } \\
\text { (SD) }(n=87)\end{array}$ & $\begin{array}{l}\text { Nurse } \\
\text { prescribers } \\
\text { Mean (SD) } \\
(n=148)\end{array}$ & $\begin{array}{l}\text { Non- } \\
\text { prescribing } \\
\text { nurses Mean } \\
\text { (SD) }(\mathbf{n}=\mathbf{8 8})\end{array}$ \\
\hline Total $\dagger^{\#}$ & & $1.88(0.52)$ & $1.98(0.58)$ & $3.51(0.76)$ & $3.47(0.79)$ & $4.21(0.50)$ & $4.13(0.54)$ \\
\hline \multicolumn{8}{|l|}{ Age (years) $\dagger^{\#,} \ddagger$} \\
\hline$\leq 40$ & & $2.10(0.48)$ & $1.83(0.34)$ & $3.08(0.32)$ & $2.90(0.83)$ & $4.25(0.29)$ & $4.36(0.24)$ \\
\hline $41-50$ & & $1.91(0.52)$ & $1.97(0.57)$ & $3.59(0.78)$ & $3.30(0.83)$ & $4.21(0.47)$ & $4.12(0.51)$ \\
\hline $51-60$ & & $1.84(0.55)$ & $1.93(0.71)$ & $3.53(0.78)$ & $3.57(0.78)$ & $4.23(0.57)$ & $4.10(0.70)$ \\
\hline$\geq 61$ & & $1.86(0.42)$ & $2.14(0.44)$ & $3.30(0.76)$ & $3.73(0.62)$ & $4.13(0.37)$ & $4.14(0.37)$ \\
\hline \multicolumn{8}{|c|}{ Professional experience } \\
\hline$\leq 15$ & & $1.95(0.42)^{\mathrm{a}^{*}}$ & $1.64(0.39)^{\mathrm{a}^{*}, \mathrm{~b}^{*}}$ & $3.47(0.90)$ & $3.10(0.78)$ & $4.19(0.44)$ & $4.37(0.34)$ \\
\hline $16-30$ & & $1.91(0.58)$ & $2.09(0.57)^{\mathrm{b}^{*}}$ & $3.55(0.76)$ & $3.54(0.90)$ & $4.23(0.52)$ & $4.04(0.56)$ \\
\hline$\geq 31$ & & $1.77(0.42)$ & $2.02(0.63)$ & $3.43(0.72)$ & $3.59(0.58)$ & $4.20(0.48)$ & $4.13(0.58)$ \\
\hline \multicolumn{8}{|c|}{ Prior use of medicines ${ }^{\sharp \#, \S}$} \\
\hline Conventional & Yes & $1.87(0.53)$ & $1.99(0.57)$ & $3.51(0.75)$ & $3.44(0.78)$ & $4.21(0.50)$ & $4.13(0.54)$ \\
\hline medicines & No & $1.93(0.45)$ & $1.85(0.87)$ & $3.53(0.94)$ & $3.67(0.98)$ & $4.18(0.52)$ & $4.31(0.69)$ \\
\hline Herbal or & Yes & $1.98(0.53)$ & $2.12(0.63)$ & $3.64(0.68)$ & $3.57(0.96)$ & $4.10(0.54)$ & $4.13(0.55)$ \\
\hline $\begin{array}{l}\text { Homeopathic } \\
\text { medicines }\end{array}$ & No & $1.84(0.51)$ & $1.95(0.57)$ & $3.46(0.80)$ & $3.42(0.75)$ & $4.26(0.48)$ & $4.14(0.54)$ \\
\hline Not used any & Yes & $2.04(0.42)$ & n.s. & $3.67(0.84)$ & n.s. & $4.07(0.45)$ & n.s. \\
\hline medicine & No & $1.86(0.53)$ & n.s. & $3.50(0.76)$ & n.s. & $4.23(0.50)$ & n.s. \\
\hline \multicolumn{8}{|c|}{ Current use of medicines ${ }^{\dagger \#, \S}$} \\
\hline \multirow{2}{*}{$\begin{array}{l}\text { Conventional } \\
\text { medicines }\end{array}$} & Yes & $1.89(0.25)$ & $1.96(0.62)$ & $3.55(0.72)$ & $3.41(0.74)$ & $4.22(0.49)$ & $4.15(0.56)$ \\
\hline & No & $1.85(0.59)$ & $2.07(0.47)$ & $3.41(0.86)$ & $3.63(0.92)$ & $4.18(0.54)$ & $4.06(0.50)$ \\
\hline \multirow{2}{*}{$\begin{array}{l}\text { Herbal or } \\
\text { Homeopathic } \\
\text { medicines }\end{array}$} & Yes & $2.07(0.45)$ & $2.08(0.69)$ & $3.65(0.75)$ & $3.33(1.11)$ & $4.07(0.53)$ & $4.14(0.57)$ \\
\hline & No & $1.85(0.53)$ & $1.98(0.58)$ & $3.49(0.77)$ & $3.47(0.76)$ & $4.23(0.50)$ & $4.13(0.54)$ \\
\hline Do not use any & Yes & $1.84(0.59)$ & $2.04(0.48)$ & $3.53(0.88)$ & $3.58(0.92)$ & $4.15(0.55)$ & $4.08(0.52)$ \\
\hline medicine & No & $1.89(0.50)$ & $1.97(0.61)$ & $3.51(0.73)$ & $3.43(0.76)$ & $4.23(0.48)$ & $4.14(0.55)$ \\
\hline
\end{tabular}

Note. Missing values not included, n.s $=\leqslant 5$ individuals in the groups no analyses made; $\dagger$ Independent $t$-test, \# tested both between and $\S$ within the two groups; $\$$ Anova test (Tukey) tested within the groups; * $p<.05$

Table 3. Differences in beliefs about medicines among nurse prescribers and non-prescribing nurses, Region Västra Götaland, Sweden, using separate linear regression models

\begin{tabular}{|c|c|c|c|c|}
\hline Models & B & SE & $\boldsymbol{\beta}$ & $p$-value \\
\hline \multicolumn{5}{|l|}{ Model (General Harm) ${ }^{\dagger}:$} \\
\hline Non-prescribing nurses & 0.10 & 0.05 & 0.09 & 0.164 \\
\hline \multicolumn{5}{|l|}{ Model (General Overuse) ${ }^{\dagger}$ : } \\
\hline Non-prescribing nurses & -0.04 & 0.10 & -0.03 & 0.676 \\
\hline \multicolumn{5}{|l|}{ Model (General Benefit) ${ }^{\dagger}$ : } \\
\hline Non-prescribing nurses & -0.08 & 0.07 & -0.08 & 0.231 \\
\hline
\end{tabular}

Notes. Nurse prescribers as reference group; missing values not included; $\uparrow$ Only the univariate models are shown in the table where General Harm, General Overuse or General Benefit were treated as the dependent variable respectively. 


\section{Discussion}

This study proceeded from the hypotheses that the right to prescribe medicines could be associated with beneficial beliefs about medicines among nurses. This was an assumption based on previous studies ${ }^{[4-6,16,17,20]}$. Our study did, however, not find any differences in general beliefs about medicines between prescribing and non-prescribing nurses. Although the data trended towards a higher mean for beneficial effects and a lower mean for harmful effects among nurse prescribers compared to non-prescribing nurses, these results were not statistically significant. The reasons for the lack of association may be several. First, the small group of non-prescribing nurses was probably a heterogeneous group comprised of both nurses with an undergraduate education only, and specialist nurses. A study with a larger population, with information about all types of specialist training, may be useful to examine if the directions and trends in the results of the current study are indeed statistically significant.

Further, in accordance with Ogden ${ }^{[15]}$, we have assumed that beliefs about medicines are similar within a specific group of health care professionals, but the variation may actually be large. Some nurses may even fill out the questionnaire based on their subjective, rather than professional views. In fact the concept of person-centered care includes personal views ${ }^{[10]}$. As an example clinical work has been seen to be influenced of personal views among Danish occupational therapists ${ }^{[28]}$. Although two Swedish studies found that type or length of medical education was a factor of importance for beliefs about medicines ${ }^{[17,20]}$ it may be the case that the right to prescribe is not associated with beliefs about medicines among nurses.

An interesting result of this study concerns the importance of nurses' professional experience. The nurse prescribers with fewer years of professional experience had more harmful beliefs about medicines compared with nurses with more years of professional experience. The results were inclined in the opposite direction for the non-prescribing nurses. This contradicts the results of the Australian study, according to which the professional experience of the nurses did not affect their beliefs about medicines ${ }^{[16]}$. We recommend that other researchers should include professional experience as a longitudinal variable in order to gain more knowledge about this factor in relation to beliefs. Furthermore, in order to further explore the importance of professional experience for beliefs, a qualitative study would be illuminating.

Two important strengths of this study are the representative study population and the validated questionnaire. The sample was randomly selected from a large Swedish county with both rural areas and large cities. Furthermore, the response rate among those nurses who received the questionnaire was high $(80.5 \%)$. Although there is always a possibility of a non-responder bias we consider this unlikely. The study population in this study did not differ from the nurses in the region according to sex and age. It is, therefore, possible to generalize the results of the study, at least to Swedish nurses.

The BMQ has been validated ${ }^{[21]}$, translated into Swedish and back-translated, as well as piloted in Sweden with good results. It has also been used in several Swedish studies, including groups of patients ${ }^{[25,26]}$ and health care professionals ${ }^{[17,20,23,24]}$.

\section{Conclusion}

At present, there is no clear indication that increasing nurses' education about medication would affect their beliefs about medicines. However, there are trends in the results that are intriguing, and which call for a larger study. There is also a need to examine the possible effect of professional experience on beliefs among nurses in greater depth. The results from this study indicate the need for an increased awareness about the importance of professional experience for beliefs about medicines during the communication between nurses and their patients.

\section{Acknowledgements}

The authors would like to thank all participating nurses for their effort and time when participating in this study. 


\section{References}

[1] The National Board of Health and Welfare. Uppföljning av förskrivningsrätten för sjuksköterskor i den kommunala hälso- och sjukvården (in swedish). Stockholm: The National Board of Health and Welfare, 2004.

[2] Latter S, Maben J, Myall M, Young A. Evaluating nurse prescribers' education and continuing professional development for independent prescribing practice: findings from a national survey in England. Nurse education today. 2007; 27: 685-96. PMid:17123668 http://dx.doi.org/10.1016/j.nedt.2006.10.002

[3] Scudder L. Prescribing patterns of nurse practitioners. J Nurse Pract. 2006; 2: 98-106. http://dx.doi.org/10.1016/j.nurpra.2005.12.019

[4] Wilhelmsson S, Foldevi M. Exploring views on Swedish district nurses' prescribing--a focus group study in primary health care. Journal of clinical nursing. 2003; 12: 643-50. http://dx.doi.org/10.1046/j.1365-2702.2003.00716.x

[5] Lewis-Evans A, Jester R. Nurse prescribers' experiences of prescribing. Journal of clinical nursing. 2004; 13: 796-805. PMid:15361153 http://dx.doi.org/10.1111/j.1365-2702.2004.00993.x

[6] Bradley E, Nolan P. Impact of nurse prescribing: a qualitative study. Journal of advanced nursing. 2007; 59: 120-8. PMid:17524048 http://dx.doi.org/10.1111/j.1365-2648.2007.04295.x

[7] Berry D, Bradlow A, Courtenay M. Patients' attitudes towards, and information needs in relation to, nurse prescribing in rheumatology. Journal of clinical nursing. 2008; 17: 266-73. PMid:18171396 http://dx.doi.org/10.1111/j.1365-2702.2007.01980.x

[8] Linn AJ, van Weert JC, Schouten BC, Smit EG, van Bodegraven AA, van Dijk L. Words that make pills easier to swallow: a communication typology to address practical and perceptual barriers to medication intake behavior. Patient preference and adherence. 2012; 6: 871-85. PMid:23271896 http://dx.doi.org/10.2147/PPA.S36195

[9] Bolster D, Manias E. Person-centred interactions between nurses and patients during medication activities in an acute hospital setting: qualitative observation and interview study. International journal of nursing studies. 2010; 47: 154-65. PMid:19577752 http://dx.doi.org/10.1016/j.ijnurstu.2009.05.021

[10] Morgan S, Yoder LH. A concept analysis of person-centered care. Journal of holistic nursing: official journal of the American Holistic Nurses' Association. 2012; 30: 6-15. PMid:21772048 http://dx.doi.org/10.1177/0898010111412189

[11] Ekman I, editor. Personcentrering inom hälsp -och sjukvård. Från filosofi till praktik. (Person-centered care in health care. From philosophy to practice). Stockholm: Liber; 2014.

[12] Ajzen I. Nature and operation of attitudes. Annu Rev Psychol. 2001; 52: 27-58. PMid:11148298 http://dx.doi.org/10.1146/annurev.psych.52.1.27

[13] Wyer Jr R, Albarracín D. Beliefs formation, organisation, and change: cognitive and motivational influences. In: Albarracín D, Johnson B, Zanna M, editors. The handbook of attitudes. Mahwa, New Jersey: Lawrence Erlbaum Associates. Inc., Publishers; 2005. 273-322.

[14] Ajzen I, Fishbein M. The influence of attitudes on behavior. In: Albarracin D JB, Zanna MP, editor. The Handbook of Attitudes. New Jersey: Lawrence Erlbaum Associates; 2005. 173-221.

[15] Ogden J. Health Psychology. Berkshire: Open University Press; 2007.

[16] Byrne MK, Deane FP, Coombs T. Nurse's beliefs and knowledge about medications are associated with their difficulties using patient treatment adherence strategies. Journal of Mental Health. 2005; 14: 513-21. http://dx.doi.org/10.1080/09638230500271378

[17] Mardby A-C, Akerlind I, Hedenrud T. General beliefs about medicines among doctors and nurses in out-patient care: a cross-sectional study. BMC Fam Pract. 2009; 10: 35. PMid:19450260 http://dx.doi.org/10.1186/1471-2296-10-35

[18] Johnson A, Hong H, Groth M, Parker SK. Learning and development: promoting nurses' performance and work attitudes. Journal of advanced nursing. 2011; 67: 609-20. PMid:20969619 http://dx.doi.org/10.1111/j.1365-2648.2010.05487.x

[19] Danielson E, Berntsson L. Registered nurses' perceptions of educational preparation for professional work and development in their profession. Nurse education today. 2007; 27: 900-8. PMid:17336430 http://dx.doi.org/10.1016/j.nedt.2006.12.007

[20] Mardby A-C, Akerlind I, Hedenrud T. Different development of general beliefs about medicines during undergraduate studies in medicine, nursing and pharmacy. Patient Educ Couns. 2009; 75: 283-9. PMid:19062234 http://dx.doi.org/10.1016/j.pec.2008.10.012

[21] Horne R, Weinman J, Hankins M. The beliefs about medicines questionnaire: the development and evaluation of a new method for assessing the cognitive representation of medication. Psychol Health. 1999; 14: 1-24. http://dx.doi.org/10.1080/08870449908407311 
[22] Horne R, Frost S, Hankins M, Wright S. "In the eye of the beholder": pharmacy students have more positive perceptions of medicines than students of other disciplines. Int J Pharm Pract. 2001; 9: 85-9. http://dx.doi.org/10.1111/j.2042-7174.2001.tb01035.x

[23] Jorgensen TM, Andersson KA, Mardby AC. Beliefs about medicines among Swedish pharmacy employees. Pharm World Sci. 2006; 28: 233-8. PMid:16691361 http://dx.doi.org/10.1007/s11096-005-2907-2

[24] Ramstrom H, Afandi S, Elofsson K, Petersson S. Differences in beliefs between patients and pharmaceutical specialists regarding medications. Patient Educ Couns. 2006; 62: 244-9. PMid:16174561 http://dx.doi.org/10.1016/j.pec.2005.07.009

[25] Mardby A-C, Akerlind I, Jorgensen T. Beliefs about medicines and self-reported adherence among pharmacy clients. Patient Educ Couns. 2007; 69: 158-64. PMid:17913439 http://dx.doi.org/10.1016/j.pec.2007.08.011

[26] Hedenrud T, Jonsson P, Linde M. Beliefs about medicines and adherence among Swedish migraineurs. Ann Pharmacother. 2008; 42: 39-45. PMid:18073328 http://dx.doi.org/10.1345/aph.1K354

[27] Altman D. Practical statistics for medical research. Boca Raton: CRC Press; 1999.

[28] Kristensen HK, Borg T, Hounsgaard L. Aspects affecting occupational therapists' reasoning when implementing research-based evidence in stroke rehabilitation. Scandinavian journal of occupational therapy. 2012; 19: 118-31. PMid:21355706 http://dx.doi.org/10.3109/11038128.2011.556197 